\title{
Situating "children-supporting-children" Platform in the Context of the Inclusive Agenda: A Phenomenological Exploration
}

\author{
Princess Zarla J. Raguindin \\ Sirib Educational Consulting, Manila, Philippines \\ https://orcid.org/0000-0002-2090-8660 \\ Li Yan Ping \\ Shaanxi Normal University, Xi'an, China \\ https://orcid.org/0000-0001-5872-320X
}

\begin{abstract}
The increasing plurality of the school population today calls for a mandate to promote inclusion in the educational systems by removing grounds that excludes and discriminates. One powerful means of promoting inclusion is through the "children-supporting-children" platform. As such, learners should be guided in the development and enhancement of social skills as a pre-requisite to a society that bars exclusion; however, less is known about it. This paper bridges this research gap by contributing to the intensive understanding and important realization on how children can become co-implementers of the inclusive agenda. A transcendental phenomenological approach was used to analyze how the teacher-participants experience and understand the context of "children-supporting-children" in the inclusive agenda as transpired in their early-grade classrooms. A semi-structured interview, focus group discussion, and class observation was conducted to gather data to (1) identify and establish their meanings and understanding of the emerging inclusive expressions and concepts exhibited by their pupils and (2) classroom strategies they employ to reinforce the constructs. A structured and inductive analysis was performed to refine the data and identify emerging codes and themes. The findings of this paper suggest that pre-schoolers are co-constructors of inclusive culture through emerging expressions and that schools are an avenue to enhance such expressions. There is limited research on specific strategies and interventions in an early childhood setting to promote inclusion; therefore, insights in this paper are relevant in implementing pro-active inclusive pedagogies as they are accounts of those who are in the field.
\end{abstract}

Keywords: inclusive education; social-emotional learning; early childhood and inclusion; teaching strategies 


\section{Introduction}

The call to implement inclusive education equally involves children with a perceived difference and their typically-developing peers (UNESCO, 2016). In the last few decades, there has been a surge of interest in how the inclusive agenda can be effectively implemented by policy-makers, school administrators, and teachers (Forlin, 2012). Recent developments in the field have led to a proliferation of studies that focuses on "pupil participation" and "voice of the child" (Pearson, 2016, p.8) in achieving inclusive goals. This forms perceptions that children have their views and agencies, which makes them powerful coimplementers of the inclusive agenda. As such, inclusion should be implemented "with children" and not "to children" (Pearson, 2016). Hence, those in the "regular curriculum" are potent levers in the promotion of a just and high-quality inclusion.

The tenet of inclusion, as enshrined in the Salamanca Statement, calls for appropriate action to educate children with special needs (CSN) alongside their peers. The statement is anchored on the premise that inclusion and participation are inherent human rights (UNESCO, 1994). Inclusive education was established to deconstruct the medical model of disability or the "Defectology" framework (Baglieri \& Shapiro, 2017; Thomas \& Loxley, 2007), which is focused on the person - with - disability and not on challenges confronting the individual. Conversely, the social model framework calls the society to redefine social policies and reshape attitudinal barriers and social arrangements (Baglieri \& Shapiro, 2017) to sustain equal opportunity - and this includes school communities.

Additionally, the Policy Guidelines on Inclusion in Education (UNESCO, 2009a) states that inclusive schools should ensure that all learners are acknowledged and valued in the learning community. The policy adheres to the idea that all stakeholders - even the typically-developing peers of the children with perceived differences- are co-creators of the inclusive school community. In the classroom context, increasing the learners' presence, participation, and collaboration are fundamental aspects of inclusion (Ahmmed, Sharma \& Deppeler, 2012, 2014; Artiles, Kozleski, Dorn \& Christensen, 2006; Booth, Ainscow \& Vaughan, 2011; Farrell, 2002; Florian, 2012; Florian \& Spratt, 2013; Forlin, 2010; Forlin, Loreman \& Sharma, 2014; Loreman \& Deppeler, 2002; Sharma \& Sokal, 2015). Among the viable options in involving learners' collective in upholding and sustaining the inclusive agenda is deconstructing marginalization and instilling inclusive values and principles - through the development and refinement of children's social competencies (Raguindin, 2020). "Super skills" lumped as social competence allow an individual to create and sustain adaptable behavior in their environment (Halle \& Darling-Churchill, 2016; Han, 2014; Han \& Kemple, 2006; Jones, Greenberg \& Crowley, 2015; Kennedy, 2018; Odom, McConnell \& Brown, 2019; Visnjic Jevtic, Lapat \& Galinec, 2019), which is significantly developed and refined during "children - to - children" interaction.

The central thesis of this paper is in the same vein with the works pursued by Pearson (2016), UNESCO (2016) and Baglieri and Shapiro (2017)that the most critical form of support to learners with perceived differences in an inclusive 
classroom is the context of "children-supporting-children" platform; however, less is still explored about it. The support children can extend to their peers contributes effectively to the inclusive approach. For example, the development of children's positive attitudes about diversity is pivotal in creating inclusive values (Pearson, 2016; UNESCO, 2016). Several inclusive indicators are emerging during early grades (Haslip, Allen-Handy \& Donaldson, 2019) and have to be developed and enhanced if schools are to affirm cultures, values, and principles that promote acceptance, belongingness, participation, collaboration, and diversity.

This qualitative paper investigated how children in the early-grades classroom value and celebrated diversity. Through an interview, focus group discussions (FGD), and classroom observation, this paper captured the lived experiences of early-grade teachers and their tacit understanding of how their learners' interdependence and support adequately achieve inclusive goals. Further, it explored the teaching strategies they utilize to co-opt children as collaborators of the inclusive agenda. Critical investigations should be done to determine essential practices that uphold a welcoming and flexible educational environment (Baglieri \& Shapiro, 2017, p. 104), consequently, enriching educational experience for all. Specifically, making collaboration and a sense of community palatable to young children creates shared classroom experiences, high-standard learning outcomes, and later in life, a society that nurtures and affirms plurality - these are all hallmarks of a high-quality inclusion.

\subsection{On expressions and concept of inclusion among young learners}

The "Diversity Wheel" (Loden, 1996) is a framework on the understanding of diversity and promoting respect, inclusion, cooperation, and responsibility. The model establishes a strong association of grounds that create exclusion and constructs like beliefs, class, gender and sexuality, physical abilities and characteristics, age, race and ethnicity, and income. The constructs are dimensions that an individual has no control; however, they are mostly the reason for discrimination and marginalization (Loden, 1996). Loden's framework is as a deductive argument, challenges institutions to create platforms for diversity conversations about mitigating exclusion - and this includes school communities. When the framework is translated to the context of inclusive education, by far, the most comprehensive facilitator of the inclusive school community is the children's adaptable skills.

This paper takes the seminal works of Piaget (1936), Erickson (1950), Sullivan (1953), Bowlby (1969), and Kohlbergb (1969) as a basis for the extension of children's role in the inclusive agenda. Although differing in practice, the authors' carried a similar emphasis that the most sensitive period in the development of social competencies in a person's life is during early childhood (McCartney \& Phillips, 2006). The claim is exhibited with how young children independently interact with peers and big groups when schooling comes. Conversely, the overlapping difficulties they experience in this domain is crucial in their adjustment and development to later adult life. Hence, guide and support should be provided during this time of transition (Denham, Bassett \& Zinsser, 2012; 
Fabes, Hanish \& Martin, 2003; Halle \& Darling-Churchill, 2016; Han \& Kemple, 2006; Haslip et al., 2019; S. M. Jones, Zaslow, Darling-Churchill \& Halle, 2016; Kennedy, 2018; Odom et al., 2019; Visnjic Jevtic et al., 2019; Yoder, 2014).

As peer interaction increases during toddlerhood, social skill significantly expands during early childhood (Han \& Kemple, 2006; Han, 2014). The literature agrees that children should become skilled in expressing their actions and feelings with others, capable of controlling, adjusting and exhibiting their emotions and behaviors appropriately during social interaction (Halle \& Darling-Churchill, 2016; Han, 2014; Haslip et al., 2019; D. Jones et al., 2015; McCartney \& Phillips, 2006; Odom et al., 2019; Visnjic Jevtic et al., 2019). Socially competent young children exhibit positive interaction among peers and can build and maintain a good relationship with others at the present and in their later adult life (Halle \& Darling-Churchill, 2016; Han, 2014; Han \& Kemple, 2006; Haslip et al., 2019; D. Jones et al., 2015; Kennedy, 2018; Odom et al., 2019; Visnjic Jevtic et al., 2019).

Additionally, social skills are not merely behaviors but are aspects of a persons' behavior that facilitates awareness and understanding of one's environment (Kennedy, 2018; Lynch \& Simpson, 2010; Steedly, Scwartz, Levin \& Luke, 2008). Social skills provide the ability for an individual for reciprocity and propriety in their social relationship (Haslip et al., 2019; Odom et al., 2019; Visnjic Jevtic et al., 2019), acceptance of diversity, capacity to thrive in a bigger group (e.g., showing empathy, participating in group activities, generosity, helpfulness, communicating with others, negotiating and problem-solving) willingness to take turns, deep respect of other's rights, and awareness and sensitivity of one's needs and others (Halle \& Darling-Churchill, 2016; Kennedy, 2018; Odom et al., 2019). Children's social skills can be grouped into competencies, like interpersonal knowledge and skills, cultural competence, and adaptive social values (Han \& Kemple, 2006; Kennedy, 2018; Lynch \& Simpson, 2010; McCartney \& Phillips, 2006; Sendil \& Erden, 2012; Yoder, 2014). These "super skills" are quintessential skills that create an "inclusive culture" as they are instrumental in establishing inclusive values and inclusive communities (Booth et al., 2011; Odom et al., 2019).

It is imperative to note that the relationship formed with peers is fundamentally different from what is developed at home. The former being freely chosen and the latter being necessitated (McCartney \& Phillips, 2006). As the nature of relationships in the schools' community is fluid, facilitators of learning should create mechanisms to support school children to develop positive learning social skills. The development of social skills entails deliberate planning and implementation of pedagogies. Subsequently, a high learning standard through the participation of learners in the "inclusive curriculum" and "standard curriculum" is facilitated and is attained(Kennedy, 2018; Odom, Buysse \& Soukakou, 2011; UNESCO, 2016).

\subsection{On classroom strategies to reinforce expressions of inclusion}

With the increasing heterogeneity in society, there is a challenge to introduce and implement new and emerging interventions, so children have opportunities to develop and refine their adaptive social behaviors. Children's social skills do not 
only address the need to establish positive social practices but also equip the children to unlearn maladaptive behaviors like aggression and other anti-social conduct (Kennedy, 2018; McCartney \& Phillips, 2006).

Previous documents showed that effective social skills instruction facilitates the emergence and refinement of social skills among young children (Han, 2014; Han \& Kemple, 2006; Haslip et al., 2019; D. Jones et al., 2015; Kennedy, 2018; Odom et al., 2019). The school environment is a critical platform through which children must learn to navigate socially. It does situate schools in two different levels - a training ground for the development of the social skills and arena to utilize those skills (Darling-Churchill \& Lippman, 2016; Halle \& Darling-Churchill, 2016; Haslip et al., 2019; S. M. Jones et al., 2016; Kennedy, 2018; Odom et al., 2019; RoseKrasnor \& Denham, 2009; Steedly et al., 2008; Visnjic Jevtic et al., 2019).

There is an endless list of teaching strategies that can be utilized in the school setting as social interaction is extensively integrated into classroom experiences and collaboration. For example is direct training - which involves explicit instruction, play strategies, problem-solving, and emotion understanding - which is the most pervasive approach in facilitating the development of social skills among children (Kennedy, 2018; McCartney \& Phillips, 2006).

Additionally, the schools' social skills curricula should strike a balance in facilitating learning individually and collaboratively. Most strategies like modeling social skills through activities, games, role play, and feedback provided by the teacher allow interaction (Kennedy, 2018; Steedly et al., 2008). Also, strategies like direct instruction, learning from a peer, prevention of problem behaviors, and children's books are useful techniques to promote social learning (Kennedy, 2018; Lynch \& Simpson, 2010).

Fox, Dunlap, Hemmeter, Joseph, and Strain (2003) proposed a hierarchy of strategies in supporting children's emerging social competence. The framework encourages teachers to begin with natural strategies such as creating meaningful relationships and facilitating a supportive classroom environment. After this, the teacher can proceed to more specific plans to provide opportunities for young learners to internalize the skills and extend these super skills to the varied social setting (Steedly et al., 2008). Social behaviors show evidence of stability during early childhood (Denham et al., 2012; Halle \& Darling-Churchill, 2016; Kennedy, 2018; McCartney \& Phillips, 2006; Rose-Krasnor \& Denham, 2009; Yoder, 2014).

Thus, the experiences children have in their formative years set a positive or negative development that will be pre-requisite to later effective interaction in their environment. Moreover, teachers as collaborators of children's learning are potential facilitators of an enhanced emotional competence for an effective societal integration (Denham et al., 2012).

Children - supporting - children platform in the context of inclusive education is a powerful means of attaining durable inclusion. The literature discussed suggests that children in the early grades are potential partners in the 
implementation of inclusive education through the cultivation of inclusive values and expression; however, it is a part of the inquiry that is mostly overlooked.

\subsection{The study}

This qualitative study set out to better understand the role of children in the inclusive agenda. Children in the early childhood stage have agencies that potentially promote inclusive values and cultures. Drawing upon the lived experiences and tacit understanding of early-grades teachers, this study investigated the emerging inclusive expressions and concepts in their early childhood classroom and the strategies they utilized to reinforce these concepts and expressions.

\section{Materials and Methods}

\subsection{Design}

Qualitative inquiry is used in this paper to address the research question as it provides answers about the real world (Marshall \& Rossman, 2016) through data which are gathered from places, events, and narrative of people (Creswell \& Creswell, 2018). Specifically, this study utilized a transcendental phenomenological approach to analyze the lived experience of the participants. Transcendental phenomenology is a variant of phenomenological approach which is focused on how the participants describe and create their meaning and understanding of the phenomenon (Moustakas, 1994 ) - in this case, the emerging inclusive concepts and expression of their early grade learners and the strategies they employ to reinforce the construct. The inclusive agenda is a research interest that the authors pursue and advocate. The need to problematize viable options in implementing inclusion, such as co-opting children as co-constructors and collaborators of an inclusive community, is of interest.

\subsection{Data gathering procedure}

From the perspective of EST, multiple means of data gathering were employed to collect sufficient and reliable information that addresses the purpose of this study. The author made use of standard open-ended interviews, focus group discussion (FGD), and classroom observation in gathering data. In the semi-structured interview, all the participants were asked the same basic questions in an openended format. Further, follow - up questions and probing questions were asked to clarify the participants' account of the phenomena being described. Each interview lasted approximately 24-26 minutes. Secondly, a focus group discussion was utilized, as it provides interaction among key actors (Creswell \& Creswell, 2018; Maxwell, 1996). The FGD influences participants' ideas, thereby enriching the description of their experiences (Creswell \& Creswell, 2018). The interview and FGD were conducted at the time and place agreed by the participants. The interview and FGD were audiotaped and transcribed for the accuracy of the accounts. To capture highlights of the responses and summary of key insights, the researcher made use of aid memoirs. Lastly, an observation was conducted to gather meaning, perspectives, and tacit understanding of the theory-in-use of the participants that were not obtained by relying exclusively on the interview and focus group discussion (Maxwell, 1996). The researcher utilized a comprehensive observation template as described by Cohen, Manion and Morrison (2002), which 
gives structure to the researcher's field notes for a full description of the observed phenomena. There were four observations conducted from different classes.

\subsection{Ethical standards}

To employ an ethical research standard, number codes for privacy and utmost confidentiality to practice research ethics were used (i.e., Teacher 1 is tagged as P1, Teacher 2 as P2, Teacher 3 as P3, and so on). Consent forms were distributed and collected to establish a clear relationship between the researcher and the participants. Further, permission to conduct a study was obtained from the gatekeepers of the schools where the participants are connected. To ensure validity and reliability in the data gathered, the researchers conducted a "member check," where the transcribed information was returned to the participant to solicit feedback about the data and conclusions derived (Creswell \& Creswell, 2018). In this way, the possibilities of misinterpretation of the meaning of the respondents' perspective, understanding, and experiences are ruled out (Maxwell, 1996). For the class observation, an after-class checking was done by the teacher of the classes observed (Cohen et al., 2002). Similarly, the informants were informed of the final themes identified in the study for review.

\subsection{Participants}

Through purposive sampling, participants who have experienced the phenomenon were selected. This paper selected 35 early-grades teachers from public and private schools from the National Capital Region of the Philippines as informants to provide data to answer the research questions. The inclusion criteria in selecting the participants of this study are (a) early childhood education background, (b) taught in an early childhood setting for a minimum of three years, and (c) is teaching in a class with a minimum class size of 15 pupils.

\subsection{Data Analysis}

The qualitative data were analyzed and refined following the structured method of inductive data analysis (Creswell \& Poth, 2017; Hall et al., 2016; Moustakas, 1994). Initially, the researcher immersed deeply into the transcripts and observation matrix to internalize the data. Next, a horizontalization was conducted to give equal weight to the sentences and quotes provided by the informants on how they experienced the phenomenon. Thirdly, the author performed a reduction to eliminate statements that were not relevant in the understanding of the informants' experiences. Additionally, a cluster of meanings was determined, and themes were assigned labels. Several clustering was done to refine the categories. Lastly, writing of textual, structural, and textualstructural descriptions was done by rereading the transcripts and cluster of meanings to determine the essence of the informants' experiences of the phenomenon.

\section{Results}

One of the hallmarks of a durable inclusive education is the participation, engagement, and high-quality learning outcomes for every member of a diverse class. In the context of an early childhood classroom, identifying the emerging inclusive concepts and expressions becomes lever in the promotion of the 
inclusive agenda. Figure 1 provides a diagram on how the context of the "children-supporting-children" platform is a powerful means of promoting inclusion.

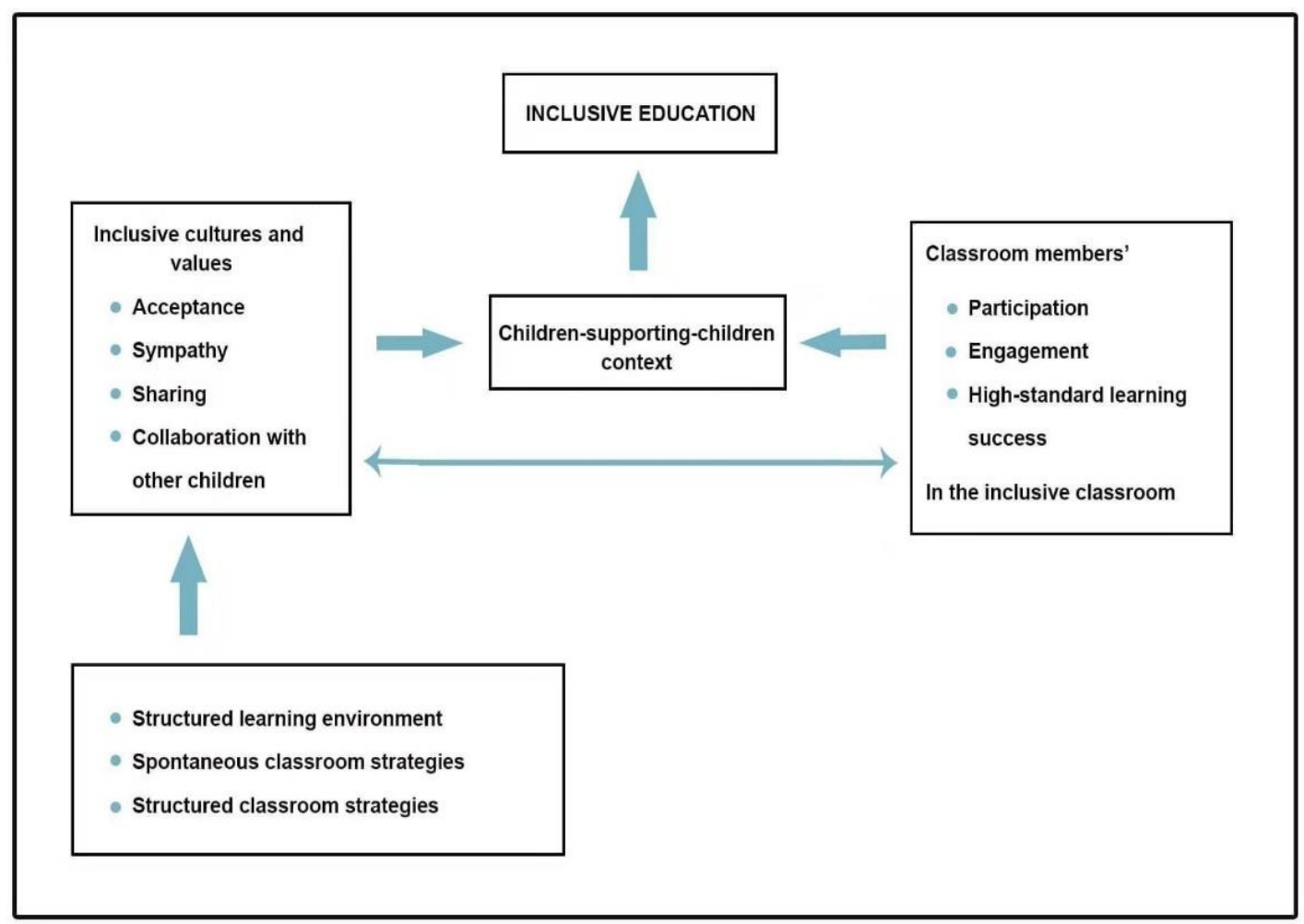

Figure 1. Dynamics of Children - supporting - children context in the inclusive agenda

\subsection{Emerging inclusive expressions of learners in the early grades}

Four themes emerged on the inclusive concepts and expressions of children in the early grades as experienced by their teachers (a) acceptance (b) sympathy (c) sharing and $(\mathrm{d})$ collaboration with other children. The informants were assigned code in the statements presented to practice confidentiality.

\section{Acceptance}

(Respect for diversity and flexibility)

The most frequent response generated from the participants is on the children's ability to show a degree of acceptance with other people in the school community. Children come to school with different personalities, clothes, and even physical appearance. It is during this stage that their emergent expression about acceptance of diversity and flexibility is observed. According to the participants, this skill is very much highlighted in the classroom, as evident in the following statements:

P14: "They have a classmate whose ears were not completely developed during birth. I observed, nobody laughs at her, neither ask her about it. [.....], everybody ignores her physical defect".

P26: "I have two Muslim students and one with atypical behavior [.....] they accept the presence of their classmates in the class". 
P8: "When we have parties, my students would always say, "Teacher, I will not bring pork." [.....] In one of our discussions, we talked about the Muslim culture".

The accounts from the key informants described how they experience the essence of acceptance as exhibited by their pupils. While in the early childhood stage, children can internalize the essence of being together in a group even when classmates have physical deformities, different religious orientations, and varied cultures.

\section{Sympathy}

(Concern for other children)

Malti, Gummerum, Keller, Chaparro, and Buchmann (2012) opined that sympathy is a pro-social behavior that entails feelings of concern and understanding of other people based on the comprehension and apprehension of the person's circumstances. Kienbaum (2014) further claimed that sympathy in early childhood is often expressed through comforting behaviors. Most participants agreed that sympathy is an emerging behavior of their pupils. There are notable instances when their pupils express some degree of sympathy with others as narrated below:

P29: "When somebody is bullied, automatically most would say, "stop it!" Then I do not need to step forward and play the sergeant-at-arms. Automatically, the class become great defenders and protectors (laughs)

P12: "It is so amazing how children consistently forgive and forget (laughs). [....] they know how to say sorry, with almost no verbal prompt from the teacher.

P3: "[...] they treat each other with care [...] when someone starts to bully her [.....] Classmates would stand behind her and advocate for her. I can see tolerance from them."

\section{Sharing}

(Taking turns, giving and receiving)

The two social skills discussed above (i.e., acceptance and sympathy) are antecedents of the skill-sharing (Malti et al., 2012). Fundamental to the development of sharing is the "ownership understanding" as it entails transferring of ownership either temporarily or permanently, which significantly takes place during early childhood and middle childhood (Brownell, Iesue, Nichols \& Svetlova, 2013; Brownell \& Pajares, 1999). Thus, while ego-centrism is apparent during toddlerhood (Feeny, Moravcik \& Nolte, 2018), sharing as a pro-social behavior emerges during early childhood (Malti et al., 2012).

The research participants described evidence of resource - sharing among their pupils in varied expressions - sharing their food, toys, and other things, as reported as follows:

P7: "[.....] pupils are self-centered regarding their things and toys or blocks [....] as classmates share, they learn to be giving most of the time." 
P26: "[...] a student who would only have boiled eggs and water for snacks, and his classmates have a lot [....] Nobody laughs at his poor snacks. Instead, they start to share and go around [...]."

P29: "Sharing has already been a part of our everyday interaction. My pupils know they should share what is inside the classroom."

\section{Collaboration with other children}

(Play, collaborative classroom activities)

As children collaborate in an activity, they develop their ability to form a balanced relationship with other people to achieve a common goal. Collaboration promotes the communication of ideas and knowledge (verbal and non-verbal) among children at a level that everybody comprehends (Goncu, 1993). Peer interaction facilitates a deep understanding of the child's social environment. This learning experience allows them to share their perspective and accommodate others' in a comfortable and nurturing ways (Goncu, 1993). This is an important skill which possesses inclusive merits. The participants reported accounts of collaboration among young children in their shared social world. To put it succinctly, collaboration in their observation is when children actively participate and guide each other towards a shared goal. Thus, they are reported below:

P27: "I have students whom I believe are born leaders [...] through collaboration, and peers were motivated by their leaders [...] The next thing I know; they all want to be leaders."

P13: "I have a cute student. She would always say, "Peacher (Teacher), I will help my classmate." And other class members will follow

P17: "I always have little teachers in my class [...] they work as team members."

It can be inferred from the accounts above how children guide other children through monitoring their peers on how to achieve a specific task.

Child-to-child support overcomes almost all forms of barriers to participation in the class. Thus, it creates an optimal learning environment for every member to thrive and succeed (UNESCO, 2016). Inclusion seeks to embrace differences in others. Learners in the "standard curriculum" should be prepared to acquire and develop competencies that mitigate exclusion. This is being achieved by providing diversity in conversations, group collaborations, and opportunities to refine adaptive social skills.

\subsection{Classroom strategies employed to develop and refine expressions of inclusion among children in the early grades}

This paper clustered three macro strategies that teacher-participants utilize to reinforced inclusive concepts and expressions among their learners. The strategies emanated from the informants are (a) structured learning environment, (b) spontaneous strategies, and (c) structured classroom strategies. 


\section{Structured learning environment}

Participants described how they utilize environmental context in reinforcing inclusive expressions among their pupils, as reported below. As defined, this context includes physical structure and organization of the classroom, routines, and the emotional environment (Han \& Kemple, 2006).

P29: "We have rules to follow in the use of learning areas like - share a toy, know when to say sorry, clean as you go, have fun with classmates."

P20: "The words sorry, please, thank you, and you are welcome are golden words in our classroom."

P18: "[...]when I see actions and hear words that will give the negative impact on other children, I am alert to process it [....] I heard my pupil say, "We do not want to play with you. You belong to another table". So I should be quick in talking to the group and make them understand the negative behavior."

P10: "I am always intentional in supporting my pupils to learn the values of being a good classmate. So even during snack time, [...] I go around and observe. During playtime, I observe. During choice time, I mingle with the kids."

Well-defined learning areas (e.g., block area, art area, science area, drama and creative corner, playhouse, among others) make the classroom for the young children an exciting place to stay while learning. Most classes observed have learning areas, especially among kindergarten classrooms. It is in these areas where turn-taking, sharing, and collaboration take place. The teachers also note that during choice time, they go around and observe small groups to ensure that the routine is instrumental in implementing the curriculum in general and targeting the multi-domain development of the learners in particular. The teacher also shared how they implement classroom rules for meaningful interaction. Simple and basic rules like using polite words, listening when somebody is talking, staying silent when needed, using quiet hands and silent feet when asked, using friendly voice, and showing friendly behaviors are among the top rules implemented in the classroom.

\section{Spontaneous Classroom Strategies}

This section is a corollary to the previous strategy. Spontaneous strategies are those that teacher employ that is naturally integrated into the whole process of learning and interaction Strategies here are implemented during routines, choice times, and instructional time. Accounts shared by the teacher also describes a strategy where they target self - regulation among children. There are times when children in their class exhibit self-centeredness. As the behavior is observed, they approach the child and explain classroom rules and regulations, more so, the relevance of displaying and expressing positive emotions. Most participants believe that this helps their pupils control their emotions and later cope with situations that bring frustration. Social reinforcement like gestures and oral language (e.g., verbal praise, smile, pat on the back, wink, high five) are effective 
means to support the development of social values. The following are vignettes from the participants on naturalistic strategies.

P32: ". I try to use positive language consistently. I avoid saying "NO,"

"DON'T," or "STOP." Instead, I would say, "Class, thank you for not laughing at your classmate."

P9: "When there is a heated situation in my class, we do not just talk about it. I do a scenario building with my pupils. I let them answer the question, "What if..?" What if you were the one who got hurt? You were the one who gets bullied? [...] And my pupils know what to do next."

\section{Structured Classroom Strategies}

This strategy is more structured as compared to the strategies discussed above. The former allows the teacher to intentionally integrate the concepts and expression in several strategies in the whole process of learning while the latter puts the teacher in reasonable anticipation of situations to reinforce the concepts and expression. The teacher plans classroom management strategies together with the learning objectives for optimal learning success (Han \& Kemple, 2006). Structured activities can be (a) group affection activities - group activities like games, plays, and songs; and (b) peer-assisted learning strategies (Han \& Kemple, 2006).

The following accounts are shared by the participants to reinforce inclusion in a structured strategy:

P10: "Role-playing is always part of lessons. It is in this way that their self-esteem is developed and, more importantly, their values."

P15: "I always let my students work with a pair or small group. I observed that they are learning to work well with their classmates. They become responsible for their groupmates."

P13: "My favorite is "Learning Barkada (group/cell)." Every week, we have a new cell group. [...] they learn to monitor each other. Everybody is also cooperative.

P2: "I facilitate meaning-making in their work. We do an art activity, and I make sure we have time to discuss their work. [....] When we do an art activity, it is either individual, by a pair or small group."

P8: "I am always careful with our worksheets. They should always be inclusive. When we talk about places in the community, I do not just put conventions. I have a Muslim pupil; I tell him to decorate the church that it will look like a mosque. So having a Muslim classmate is already a natural situation in my class."

All participants reported that group affection strategies are effective means to increase the likelihood of enhancing social skills among children in the early grades. 


\section{Discussion}

To be a successful member of a diverse environment, there are different competencies one should possess (Denham et al., 2012; Han \& Kemple, 2006; S. M. Jones et al., 2016; Kennedy, 2018; Rose-Krasnor \& Denham, 2009) - like acceptance, sympathy, sharing, collaboration. Katz and McClellan (1997) posited that competent social individuals are those who engage in a meaningful relationship with peers and adults. Thus, social competence is a parameter of successful human interaction and integration and thus a pre-requisite to a community that removes pressures to exclude (UNESCO, 2016). In the early childhood context, there is a need to decide and orchestrate strategies on how to develop and enhance the social skills of young children toward creating and sustaining meaningful relationships.

Enhancing the culture and value of acceptance in a diverse group is a prelude to a community that bars any form of marginalization. This data further confirms that early childhood is a transition from infancy and toddlerhood where children experience solitary play and almost slim chances for social interaction (Han, 2014; Jones et al., 2015; Odom et al., 2019). As children approach early childhood, their repertoire of social skills such as acceptance of other people emerges (Jones et al., 2015; Kennedy, 2018; Odom et al., 2019). It is stated from the scripts that differences are so much evident in their classes, but children exhibit recognition with the way they relate with their peers.

Although the children's expression of acceptance may not significantly remove all tensions in the class, there are notable high-level of acceptance with their peers (Kennedy, 2018; Visnjic Jevtic et al., 2019), which is integral in sustaining welcoming classroom environment (Baglieri \& Shapiro, 2017). On the other hand, this notion of acceptance is collective as it is manifested with peers and even reinforced by the classroom teacher (Odom et al., 2011; UNESCO, 2016). From the foregoing, one could deduce that social value often included in early childhood development research is the value of community. Being part of a wider community, a school for this matter requires that children bring with them emerging awareness that they are part of a larger group. Thus, being considerate of others become a skill that is beneficial to the group, themselves, and of others (Baglieri \& Shapiro, 2017; Han, 2014; Han \& Kemple, 2006; D. Jones et al., 2015; Kennedy, 2018; Odom et al., 2019; Pearson, 2016). Acceptance strongly coincides with the active call to promote inclusive communities.

Next, sympathy as a pro-social skill is a pre-requisite to the development of perspective-taking skills in middle childhood, and eventually, throughout the life span. Perspective-taking is when the feeling of negative emotions when someone else is experiencing distress is shared and felt by another person (Malti et al., 2012). Thus, sympathy removes pressures to exclude (Malti et al., 2012) as children learn to value others' feelings and circumstances (Kennedy, 2018; Odom et al., 2019)

Pro-social skills like acceptance and sympathy are directly related to the person's ability to express skills of sharing. The experience of a child being around with other children is not enough to develop social skills. It is essential that they build 
rapport with each other to establish meaningful reciprocal interactions. Opportunities to interact with classmates early on in the early childhood setting is an avenue to refine values of sharing (National Scientific Council on the Developing Child, 2004). Sharing promotes the community as it is a form of otheroriented value, thereby highlighting inclusion in the diverse community.

Collaboration with other children provides an opportunity for the children to stretch their cognitive and social skills (Haslip et al., 2019; Kennedy, 2018; Visnjic Jevtic et al., 2019). They facilitate social skills that later would become significant in promoting a classroom that celebrates diversity. The social skills - sharing, sympathy, collaboration, acceptance of diversity- are all social skills in early childhood that directly appeals to the value of community (Odom et al., 2019). Building a sense of appreciation, acceptance, and participation in the classroom community requires children to have an emerging awareness that they are part of a large group (Han, 2014; Han \& Kemple, 2006; Odom et al., 2019). Thus, they represent critical factors like acceptance, participation, and achievement, which are relevant standards of a pro-active inclusive practice.

A wide variety of strategies are warranted to support the development of social competence like acceptance, sympathy, sharing, and collaboration among young children. Fox et al. (2003) provided a hierarchy of strategies to support a meaningful and supportive classroom environment. Han (2014) also presented models to organize the strategies used by the teachers to reinforce expressions of inclusion- environmental arrangements, natural strategies, and planned routine activities. While concepts and expressions of inclusion are still emerging in the early grades, it is also an opportune time to reinforce these expressions as children refine their social skills. Strategies under the domain of environmental arrangement are among the crucial strategies because it is here that children interact with other children beyond the watch of an adult. It is during this time when they do not need to modify their language and actions to meet the expectations of adults. Thus, these are times when there are no inhibitions, and the teacher can intensively observe their actual behavior during peer interaction (Han \& Kemple, 2006).

Further, spontaneous strategies necessitate the teacher's awareness, quick thinking, and thoughtful, intentional use of strategies but only involves a minimum amount of time and effort from the teacher to implement managerial role in the classroom - conflict mediation and on-the-spot support (Kemple, 2004). Han and Kemple (2006) defined "conflict meditation" as the process where the teacher provides the much-needed scaffolding to support children's development and enhancement of their ability to resolve conflict through spontaneous verbal arguments without aggression. Further, "on-the-spot support" (Ramsey, 1991, 2008) deals with coaching and modeling, which takes place in a very natural context. These are strategies where a verbal prompt is utilized by the teacher to reinforce a specific social skill. Conroy and Brown (2002) claimed that this strategy calls for "incidental teaching." 
Structured activities promote peer interaction and collaboration by creating a nonthreatening atmosphere through fun activities (Han \& Kemple, 2006). Meaningful group work presents different gains. Central to the completion of a task is the active participation and significant contribution of each member in the group and that one member cannot succeed without the success of others. This then produces the need for each member to contribute and interact with the whole group in positive ways (UNESCO, 2016). Participation, and achievement of each member in a group are reflective of an acceptable standard of inclusion.

This study produced results which corroborate the findings of a great deal of previous work in the development of children's social skills in sustaining and upholding th tenets of inclusion (Baglieri \& Shapiro, 2017; Han \& Kemple, 2006; D. Jones et al., 2015; S. M. Jones et al., 2016; Kennedy, 2018; Malti et al., 2012; McCartney \& Phillips, 2006; Odom et al., 2019; Pearson, 2016; UNESCO, 2009b, $2016,1994)$. To promote inclusive culture and values in the society through the classroom, it is an imperative for educational institutions to (a) integrate cultures like acceptance, sympathy, collaboration, \& celebration of diversity, and (b) put high regard on intentional, appropriate and meaningful use of instructions, prompts, rehearsals, feedback mechanisms, discussions, diversity conversations, and specific combinations of these procedures. Moreover, classroom experiences improve young children's useful establishment of a social relationship with their peers - a pre-requisite to a culture that upholds and sustains inclusion amid increasing heterogeneity.

\section{Conclusion}

In a diverse community, themes, and pressures that excludes are becoming ubiquitous and evolving (Brown \& Palaiologou, 2016). One means to combat exclusionary cultures and values is to promote the concept that "everyone belongs to a group, no matter what." For Brown and Palaiologou (2016), leading children in the process of inclusive pedagogical practices and embedding cultural relativism (p.75) is a powerful means of achieving inclusion and combating exclusion in the early childhood classroom. The claim can be supported by targeting the development and enhancement of children's social skills to promote inclusive cultures and promote diversity.

This study adds to the growing body of evidence that suggests that there are emerging inclusive concepts and expressions in an early childhood setting (e.g., acceptance, sympathy, sharing, and collaboration). The findings surfaced new ways of claiming that "children supporting children" context is a powerful platform in the implementation of inclusion (Baglieri \& Shapiro, 2017; Pearson, 2016; UNESCO, 2016). Children, who were once regarded as a passive part of the inclusive agenda, are co-constructors of inclusive communities as they are considered valuable experts in their culture (Brown \& Palaiologou, 2016, p. 75) who have agency and voice. Therefore, it is essential to plan and implement learning experiences that promote the development and refinement of social skills among young children to support them to promote an inclusive culture and celebrate diversity. 


\subsection{Significance of the Study}

The combination of findings in this study provides some support for the conceptual premise that early childhood is the onset of the development of social skills -including expressions of inclusion - and that they are potent levers in achieving inclusive goals. Hence, strategies that enhance this "super skill" should be carried out in the school curriculum. For example, social skills should be integrated into a systematic and well-defined curricular framework and practice to ensure support in the positive social development of children. Second, teachers should consistently reflect, plan, implement, and evaluate intentional strategies by which inclusive expressions are reinforced in the early grade. Child-to-child interaction provides significant potential in refining pro-social behaviors, more so, in the attainment of a just and inclusive community of learners. On the other hand, teacher and staff collaboration facilitates pro-active and consistent modeling of pro-social skills among children and the whole school community. Finally, the findings might help educators to prioritize play as a context for the development and refinement of social skills that is beneficial to children, especially in early childhood. Types of play like exploratory, constructive, creative, pretend, fantasy, socio-dramatic, physical, and language play provide meaningful and spontaneous experiences to children, which has a direct relationship to the development and refinement of their social competence.

In an era where plurality significantly increases, and educational agency pushes towards pro-active inclusive practices, regular classrooms must implement effective school strategies and orchestrate the development and enhancement of inclusive expressions. The process of expanding the participation and interaction of all members of the school community reduces pressures to exclude (Baglieri \& Shapiro, 2017; Pearson, 2016; UNESCO, 2016) thereby, promoting a positive learning environment where all children, with or without perceived differences, learn, thrive and experience optimal success in the teaching-learning process.

\subsection{Limitations of the Study}

This paper addressed the research problem through the lenses of early childhood Filipino educators and did not attempt to gather insights from the early graders themselves. Also, findings cannot demographically represent the experiences of teachers from other geographical locations, and learners from different grade levels. To develop a full picture of the claim of this paper, additional studies are needed to determine what are other concepts and expressions children from other contexts (geographical location, culture, and grade levels) possess, which can be a potential facilitator of inclusive school communities. Further, studies that will take the variables in this paper into account will need to pursue the possibility of advancing the teachers' competence in developing and enhancing children's social skills.

\section{References}

Ahmmed, M., Sharma, U., \& Deppeler, J. (2012). Variables affecting teachers' attitudes towards inclusive education in Bangladesh. Journal of Research in Special Educational Needs, 12(3), 132-140. https://doi.org/10.1111/j.14713802.2011.01226.x

Ahmmed, M., Sharma, U., \& Deppeler, J. (2014). Variables affecting teachers' intentions to 
include students with disabilities in regular primary schools in Bangladesh. $\begin{array}{llll}\text { Disability } & \text { S } & \text { Society, } & \text { 317-331. }\end{array}$ https://doi.org/10.1080/09687599.2013.796878

Artiles, A., Kozleski, E., Dorn, S., \& Christensen, C. (2006). Chapter 3: Learning in Inclusive Education Research: Re-mediating Theory and Methods With a Transformative Agenda. Review of Research in Education - REV RES EDUC, 30, 65-108. https:// doi.org/10.3102/0091732X030001065

Baglieri, S., \& Shapiro, A. (2017). Disability studies and the inclusive classroom. Critical practices for embracing diversity in education (2nd Ed.). New York, NY: Routledge.

Booth, T., Ainscow, M., \& Vaughan, M. (2011). Index for Inclusion. Developing Learning and Participation in Schools. Retrieved from http://www.csie.org.uk/resources/inclusion-index-explained.shtml

Brown, Z., \& Palaiologou, I. (2016). Inclusive practice in early childhood education. In Z. Brown (Ed.), Inclusive education. Perspectives on pedagogy, policy, and practice. New York, NY.

Brownell, C. A., Iesue, S. S., Nichols, S., \& Svetlova, M. (2013). Mine or yours? Development of sharing in toddlers in relationship to ownership understanding. Child Development, 84(3), 906-920.

Brownell, M. T., \& Pajares, F. (1999). Teacher Efficacy And Perceived Success In Mainstreaming Students With Learning And Behavior Problems. Teacher Education and Special Education, 22(3), 154-164. https://doi.org/10.1177/088840649902200303

Cohen, L., Manion, L., \& Morrison, K. (2002). Research methods in education. Routledge.

Conroy, M. A., \& Brown, W. H. (2002). Preschool children: Putting research into practice. Promoting Social Communication: Children with Developmental Disabilities from Birth to Adolescence, 211-238.

Creswell, J. W., \& Poth, C. (2017). Qualitative inquiry and research design: Choosing among five approaches (4th Ed.). Thousand Oaks, CA: Sage publications.

Creswell, J. W., \& Creswell, J. D. (2018). Research design: Qualitative, quantitative, and mixedmethods approaches (5th ed.). Thousand Oaks, CA: SAGE Publication.

Darling-Churchill, K. E., \& Lippman, L. (2016). Early childhood social and emotional development: Advancing the field of measurement. Journal of Applied Developmental Psychology, 45, 1-7. https://doi.org/10.1016/j.appdev.2016.02.002

Denham, S., Bassett, H., \& Zinsser, K. (2012). Early childhood teachers as socializers of young children's emotional competence. Early Childhood Education Journal, 40(3), 137-143.

Fabes, R. A., Hanish, L. D., \& Martin, C. L. (2003). Children at Play: The Role of Peers in Understanding the Effects of Child Care. Child Development, 74(4), 1039-1043. Retrieved from http://www.jstor.org/stable/3696202

Farrell, P. (2002). Making special education inclusive: from research to practice (M. Ainscow \& P. Farrell, eds.). London, UK: David Fulton.

Feeny, S., Moravcik, E., \& Nolte, S. (2018). Who am I in the lives of Children? An introduction to early childhood education (11th ed.). New York, NY: Pearson Education Limited.

Florian, L. (2012). Preparing Teachers to Work in Inclusive Classrooms: Key Lessons for the Professional Development of Teacher Educators from Scotland's Inclusive Practice Project. Journal of Teacher Education, 63(4), 275-285. https://doi.org/10.1177/0022487112447112

Florian, L., \& Spratt, J. (2013). Enacting inclusion: A framework for interrogating inclusive practice. European Journal of Special Needs Education, 28. https://doi.org/10.1080/08856257.2013.778111 
Forlin, C. (2010). Teacher Education for inclusion. Changing paradigms and innovative approaches (Chris Forlin, ed.). London, England: Routledge.

Forlin, C. (2012). Future directions: What is needed now for effective inclusive teacher education? In C. Forlin (Ed.), Future Directions for Inclusive Teacher Education. An international perspective (pp. 173-183). New York, NY: Routledge.

Forlin, C., Loreman, T., \& Sharma, U. (2014). A system-wide professional learning approach about inclusion for teachers in Hong Kong. Asia-Pacific Journal of Teacher Education, 42(3), 247-260. https:/ / doi.org/10.1080/1359866X.2014.906564

Fox, L., Dunlap, G., Hemmeter, M. L., Joseph, G. E., \& Strain, P. S. (2003). The Teaching Pyramid: A Model for Supporting Social Competence and Preventing Challenging Behavior in Young Children. Young Children, 58(4), 48-52.

Goncu, A. (1993). Development of intersubjectivity in social pretend play. Human Development, Vol. 36, pp. 185-198. https://doi.org/10.1159/000278206

Hall, E., Chai, W., \& Albrecht, J. A. (2016). A Qualitative Phenomenological Exploration of Teachers' Experience With Nutrition Education. American Journal of Health Education, 47(3), 136-148. https:/ / doi.org/10.1080/19325037.2016.1157532

Halle, T. G., \& Darling-Churchill, K. E. (2016). Review of measures of social and emotional development. Journal of Applied Developmental Psychology, 45, 8-18. https:// doi.org/10.1016/j.appdev.2016.02.003

Han, S. (2014). Supporting Early Childhood Teachers to Promote Children's Social Competence: Components for Best Professional Development Practices. Early Childhood Education Journal, 42. https:// doi.org/10.1007/s10643-013-0584-7

Han, S., \& Kemple, K. (2006). Components of Social Competence and Strategies of Support: Considering What to Teach and How. Early Childhood Education Journal, 34, 241-246. https:// doi.org/10.1007/s10643-006-0139-2

Haslip, M., Allen-Handy, A., \& Donaldson, L. (2019). How do Children and Teachers Demonstrate Love, Kindness and Forgiveness? Findings from an Early Childhood Strength-Spotting Intervention. Early Childhood Education Journal. https://doi.org/10.1007/s10643-019-00951-7

Jones, D., Greenberg, M., \& Crowley, D. (2015). Early Social-Emotional Functioning and Public Health: The Relationship Between Kindergarten Social Competence and Future Wellness. American Journal of Public Health, 105, 1-8. https:// doi.org/10.2105/AJPH.2015.302630

Jones, S. M., Zaslow, M., Darling-Churchill, K. E., \& Halle, T. G. (2016). Assessing early childhood social and emotional development: Key conceptual and measurement issues. Journal of Applied Developmental Psychology, 45, 42-48. https://doi.org/10.1016/j.appdev.2016.02.008

Katz, L. G., \& McClellan, D. E. (1997). Fostering children's social competence: The teacher's role. Washington, DC: NAEYC.

Kemple, K. M. (2004). Let's be friends: Peer competence and social inclusion in early childhood programs. Teachers College Press.

Kennedy, A. (2018). Promoting the Social Competence of Each and Every Child in Inclusive Early Childhood Classrooms. https://doi.org/10.5772/intechopen.80858

Kienbaum, J. (2014). The development of sympathy from 5 to 7 years: Increase, decline, or stability? A longitudinal study. Frontiers in Psychology, 5, 468. https:// doi.org/10.3389/fpsyg.2014.00468

Loden, M. (1996). Implementing diversity: Best practices for making diversity work in your organization (J. Krames, Ed.). Toeledo, OH: McGraw-Hill, Education.

Loreman, T., \& Deppeler, J. (2002). Working towards full inclusion in education. Access: The National Issues Journal for People with a Disability, 3(6), 5-8. 
Lynch, S., \& Simpson, C. (2010). Social Skills: Laying the foundation for success. Dimensions of Early Childhood, 38(2), 3-12.

Malti, T., Gummerum, M., Keller, M., Chaparro, M. P., \& Buchmann, M. (2012). Early sympathy and social acceptance predict the development of sharing in children. PloS One, 7(12), e52017-e52017. https://doi.org/10.1371/journal.pone.0052017

Marshall, C., \& Rossman, G. (2016). Designing qualitative research (6th Ed.). Thousand Oaks, CA: SAGE.

Maxwell, J. (1996). Qualitative research design. An interactive approach. Thousand Oaks,CA: SAGE.

McCartney, K., \& Phillips, D. (2006). Blackwell handbook of early childhood education. Massachusetts: Blackwell Publishing.

Moustakas, C. (1994). Phenomenological research methods. https:// doi.org/10.4135/9781412995658

National Scientific Council on the Developing Child. (2004). Young children develop in an enviroment of relationships: Working paper No.1 (No. Working Paper No.1).

Odom, S., Buysse, V., \& Soukakou, E. (2011). Inclusion for Young Children With Disabilities: A Quarter Century of Research Perspectives. Journal of Early Intervention - J EARLY INTERVENTION, 33, 344-356. https://doi.org/10.1177/1053815111430094

Odom, S., McConnell, S., \& Brown, W. (2019). Social competence of young children: Conceptualization, assessment, and influences. In W. Brown, S. Odom, \& S. McConell (Eds.), Social competence of young children: Risk, disability, and intervention (pp. 3-29). Baltimore, MD: Paul H. Brookes Publishing.

Pearson, S. (2016). Rethinking children and inclusive education. Opportunities and complexities. London, UK: Bloomsbury Academic.

Raguindin, P. Z. J. (2020). Integrating Concepts and Expressions of Inclusion in the K Curriculum: The Case of the Philippines. European Journal of Educational Research, 9(1), 305-317.

Ramsey, P. (1991). Making friends in school: Promoting peer relationships in early childhood. New York: Teachers College Press.

Ramsey, P. (2008). Children's responses to differences. NHSA Dialog, 11(4), 225-237.

Rose-Krasnor, L., \& Denham, S. (2009). Social-emotional competence in early childhood. Handbook of Peer Interactions, Relationships, and Groups, 162-179.

Sendil, C. O., \& Erden, F. T. (2012). Preschool Teachers' Strategies to Enhance Social Interaction Skills of Children during Playtime. Procedia - Social and Behavioral Sciences, 47, 918-923. https:// doi.org/10.1016/j.sbspro.2012.06.757

Sharma, U., \& Sokal, L. (2015). The impact of a teacher education course on pre-service teachers' beliefs about inclusion: An international comparison. Journal of Research in Special Educational Needs, 15(4). https://doi.org/10.1111/1471-3802.12043

Steedly, K., Scwartz, A., Levin, M., \& Luke, S. (2008). Social skills and academic achievement. Evidences for education. National Center for Children with Disabilities, $3(11), 1-7$.

Thomas, G., \& Loxley, A. (2007). Deconstructing Special Education Reconstructing Inclusion.

UNESCO. (1994). The Salamanca Statement and Framework for Action. Policy, (June), 710. Retrieved from http:/ / unesdoc.unesco.org

UNESCO. (2009a). Guidelines for inclusion: ensuring access to education for all. Retrieved from http://unesdoc.unesco.org

UNESCO. (2009b). Policy guidelines on inclusion in education. Retrieved from http:// unesdoc.unesco.org

UNESCO. (2016). Training tools for curriculum development. Reaching out to all learners: A 
resource pack for supporting inclusive education. Retrieved from http://www.unesco.org/education/pdf/15_62.pdf

Visnjic, J. A., Lapat, G., \& Galinec, M. (2019). The Role of Early Childhood Education in Developing Social Competence of Roma Children. 20, 77-91. https://doi.org/10.15516/cje.v20i0.3323

Yoder, N. (2014). Teaching the whole child: Instructional practices that support social-emotional learning in three teacher evaluation framework. Washington, DC: American Institutes for Research Center on Great Teachers and Leaders. 